\title{
Consistency and Creativity in First Language Acquisition
}

\author{
MICHAEL ISRAEL \\ University of Maryland, College Park
}

\section{Creativity in a Usage-Based Grammar}

Creativity poses a problem for linguistic theory (Braine 1971; Bowerman 1988, 1996; Pinker 1989). The problem is that speakers do not just reuse linguistic formulae they have heard before, but creatively manipulate language to form and interpret novel utterances. To do this, speakers require relatively abstract knowledge of linguistic structures, and children must somehow acquire this knowledge. Children, however, not only learn how to produce novel grammatical utterances, but also how to avoid ungrammatical ones. To do this, they must somehow discover the limits on the productivity of grammatical patterns. The problem of how children avoid constructing an over general grammar (Braine and Brooks 1995) thus turns on a basic tension between a need to use language creatively, and a need to conform to the usage one hears: the former requires relatively abstract linguistic representations, the latter requires specific knowledge about what sorts of things people actually say.

In this paper I argue that a general PRINCIPLE OF CONSISTENCY both motivates and constrains the process of analogical learning in a usage-based grammar. The basic idea is that children learning a language, and speakers in general, represent linguistic units in ways that maximize their motivation and emphasize their commonalities. Two units are consistent with each other to the degree that they match in their formal and semantic specifications. LOCAL CONSISTENCY applies to linguistic units activated online in usage events, and requires these to be as consistent as possible with entrenched utterance types. GLOBAL CONSISTENCY applies to the repertoire of constructions as a whole, and requires that units be represented in ways which maximize their consistency with each other. Local consistency favors a massive inventory of low-scope constructions to represent the rich details of experienced usage events: it thus fosters arbitrariness in the grammar, but also makes on-line processing easier by offering conventional units for every occasion. Global consistency favors the development of abstract representations and recurrent inheritance links across constructions: it thus increases motivation in 
the grammar, but also makes processing harder as the schematic units it favors are farther removed from the details of actual usage.

Global consistency motivates the emergence of schematic linguistic units which can license novel utterances; local consistency constrains the use of such units by encouraging conformance to familiar patterns of usage. The effects of consistency should be apparent in the ways children do-or systematically do not-use grammatical constructions creatively, and the bulk of this paper will therefore focus on the varieties of creativity observable in young children's use of a set of constructions featuring non-finite complement clauses. However, before we examine the consistency principle's empirical teeth, it may help to consider its theoretical roots in the usage-based theory of Cognitive Grammar (Langacker 1987, 1991, 1999).

This theory starts with the assumption that a grammar is a system of internalized cognitive routines which emerge to meet the exigencies of language use. More precisely, a grammar represents a speaker's knowledge of linguistic convention, and consists of a structured inventory of linguistic units, including phonological, semantic, and symbolic structures, represented with varying degrees of internal complexity, and at varying levels of abstraction (Langacker 1987: 73). The inventory is structured by a complex network of inheritance links marking partwhole, type-token, and based-on relations between units. The relation between grammar and usage is one of categorization. Linguistic units activated in usage serve to categorize, and so to sanction usage events. Usage events (or aspects thereof) which for some reason cannot be categorized, or which diverge too sharply from the specifications of a sanctioning structure, are experienced as either ungrammatical or uninterpretable. Typically, linguistic units will compete to be activated as the sanctioning structure for a given usage event: factors favoring selection include (i) priming (recency of prior activation), (ii) entrenchment (frequency of prior activation), and (iii) specificity (closeness of match to target structure). Often, an entire utterance may be sanctioned by a single, frequently recurring complex unit (e.g. how do you do); other times, more abstract constructions may be required to sanction the composition of two or more units in a complex whole.

Given these basic assumptions, language acquisition involves nothing more than the accumulation of linguistic units and the discovery of relations between them. All units are learned from experience, either as (parts of) overtly occurring expressions, or else as schematizations over previously mastered units. Acquisition begins with simple and concrete units (e.g. bye-bye, all gone, mine, what dat?) which the child can employ directly in the performance of specific linguistic acts. The emergence of flexible and creative use depends on the discovery of regular and recurring patterns found across a range of familiar utterance types. Such patterns are entrenched as (relatively) abstract constructional schemas capable of licensing a (potentially) open-ended set of utterance tokens. At first, such schemas will be very concrete, involving simple slot and frame structures based on specific uses of 
specific lexical items. Later, these may form the basis for further abstractions, as schemas are built on schemas to capture increasingly higher-order grammatical generalizations.

In principle, there is no limit to how abstract constructions can become, but there is a real question as to how much abstraction is necessary (cf. Tomasello 2000 a, Fisher 2002). Recent work on child language points increasingly to the role of concrete, item-based units and frequency driven learning in the development of grammatical competence (e.g. Pine, Lieven \& Rowland 1997; Tomasello 2000b); at the same time, work in connectionist modeling, language processing, and corpus linguistics has been converging on a view of linguistic structure which is massively usage-based and frequency driven (see, for example, recent papers in Barlow \& Kemmer 2000, and Bybee \& Hopper 2001). As a consequence, some researchers have become skeptical about the importance-or even the existence - of abstract linguistic representations. But there is no reason grammars should not include both concrete and abstract representations. Indeed, the consistency principle suggests that the two should in principle be inseparable, and that abstract schemas emerge in tandem with and as a function of an expanding repertoire of item-specific constructions. In this paper I will argue that while early grammatical representations are indeed massively item-based, from an early age children also seem to be sensitive to relatively abstract similarities across construction types.

\section{Consistency and Non-finite Complement Clauses}

The operation of consistency as a developmental principle makes four basic predictions about the development of abstract representations in child language: (i) Constructional Grounding-complex constructions will tend to be based on simpler, previously entrenched routines; (ii) Early Agrammaticality-early creative combinations may be (in some ways) the least constrained, since early on children will lack consistent patterns on which to model their own; (iii) Interference Effects-constructions with superficial similarities may be linked in ways that trigger performance errors or other confusions; (iv) Persistence - the more motivations an innovation has, (i.e. the more consistent it is with a child's overall repertoire of constructions), the more likely it is to persist.

Basically, we want to know how abstract child grammar gets, and how it gets as abstract as it does. Crucially, this means we need some way of observing abstractions in the concrete behavior of children's spontaneous usage. In this paper, I will be less concerned with the precise representation of children's linguistic structures, and more with the ways children's spontaneous productions may provide evidence for abstract representations in general. To this end I examine the emergence of non-finite complement clause (NFCC) constructions in seven children between the ages of $1 ; 6$ and 5 years, and identify four types of creative combinations typical of children's spontaneous usage.

Data comes from the ReVerb project (Israel, Brooks, \& Tomasello, in progress), which coded the inflection, argument structure, and complement array of every instance of every verb in the spontaneous speech of seven children from the 
Childes database (MacWhinney 1995). The particular constructions under study, NFCCs, form a family of related utterance types, all of which feature a matrix verb, a surface direct object and a non-finite complement of any category (X-Comp) predicated of the direct object. The examples in (1a-c) illustrate typical NFCC constructions. The schema in (2) captures some of the basic structural features which unite them.
(1) a. that $\left[\right.$ make $\left._{\text {matrix }}[\text { it dark outside }]_{\mathrm{NFCC}}\right]$.
Eve 2;0
b. [put matrix $_{\text {man }}$ on the shelf $]_{\text {NFCC }}$.
Nina $2 ; 1$
c. I'm gonna [ get $\left._{\text {mat }}[\text { the cow to drink some milk] }]_{\mathrm{NFCC}}\right]$.
Peter $2 ; 8$

$\left[\left(\mathrm{NP}_{1}\right)\left[\mathrm{V}_{\text {matrix }}\left[\mathrm{NP}_{2} \mathrm{X}-\mathrm{Comp}\right]_{\mathrm{NFCC}}\right]\right]$

A motley array of constructions fits this pattern: the schema abstracts over adjectival, prepositional, and verbal X-Comps, and ignores differences between raising, control, and small clause structures, among others. But while these structures may not form a single, coherent category in the grammar of English, they are, in many ways, globally consistent with each other: they share the same basic word order, reflecting a common, general strategy for encoding complex propositions in a single, finite clause. The question is how children learn to differentiate these constructions without being misled by their surface similarities. Given these similarities, this extended family of constructions offers fertile ground for grammatical innovations and overgeneralizations, and so provides an ideal laboratory in which to observe early linguistic creativity.

In the rest of this paper, I will concentrate on some of the more interesting ways the ReVerb children use NFCC constructions, and I will identify four classes of creative usage which bear out the consistency principle's four predictions about linguistic representation: the gradual emergence of flexible routines illustrates the process of constructional grounding; children's groping patterns attest to the role of early agrammaticality; various mixed constructions illustrate interference effects; and finally, two examples of novel constructional blends attest to the persistence of well-motivated innovative forms.

\section{Constructional Grounding and Flexible Routines}

Creativity comes in a variety of forms. We are concerned here with the productive use of familiar expressions in novel combinations - creativity which depends on the schematic representation of complex patterns across utterance types. Such representations are most evident when children say things they are unlikely to have heard elsewhere. When Eve at 2;2 says I falled that down, we can attribute this novel usage to the child's recognition of the abstract relation between causative and inchoative uses of other verbs like break, open and grow (cf. Bowerman 1996). Children may also produce utterances which appear thoroughly conventional, but which are just as novel from the child's perspective. This kind of creativity is 
harder to observe, but given the formulaic nature of early child language, it can be seen in the ways particular item-based routines gradually take on more and more flexible usages. Indeed, I will argue that it is precisely the gradual process of loosening up formerly rigid utterance routines that allows children to develop accurate and increasingly abstract representations of sentence structure. Local consistency limits the degree to which novel utterances may diverge from established patterns, and so ensures that new, more abstract patterns should emerge as extensions from or elaborations of simpler and more concrete linguistic units. This is what Johnson (1999:8) calls constructional grounding--a process whereby complex linguistic signs may be learned as special cases of other, simpler signs with overlapping distributions and similar constructional properties. In this case, the simple signs are unanalyzed low-scope formulae and the complex signs are the abstract constituency and valence constructions which these formulae instantiate. In this sense, low-scope, item-based constructions are not just a sign of children's underdeveloped grammatical abilities; they may in fact be the foundation on which more sophisticated and abstract grammar is built.

There is no shortage of evidence that many NFCC constructions start off as low-scope formulae. Adam's use of the verb want is a dramatic example. Most children use want mainly to express indirect requests (e.g. I want $X$ ) and to form indirect suggestions (e.g. do you want $X$ ?). In Adam's case, the tendency is strikingly exceptionless: over five months, between the ages of 2;9 and 3;2, all 179 instances of Adam's want + NFCC utterances are, like those in (3), $2^{\text {nd }}$ person, present tense questions, used for the most part to seek approval for a proposed course of action Adam would like to pursue. Around 3;3, Adam expands his usage to include $1^{\text {st }}$ person, present tense assertions like those in (4), which directly report his current desires. By the age of 5;2, with 301 examples in the entire corpus, Adam has only 8 instances of want + NFCC which do not conform to one of these narrow usages.

$\begin{array}{lll}\text { wan(t) me open it ? } & 2 ; 9.4 & \text { Adam 13 } \\ \text { want me get out ? } & 2 ; 9.18 & \text { Adam 14 } \\ \text { do want me ride it ? } & 2 ; 10.30 & \text { Adam 17 } \\ \text { d(o) you want me drink hot coffee ? } & 2 ; 10.30 & \text { Adam 17 } \\ \text { d(o) you want me \# put hole in? } & 2 ; 11.13 & \text { Adam 18 } \\ \text { do want he talk? } & 2 ; 11.13 & \text { Adam 18 } \\ & & \\ \text { I don't want you to take it out \# Mommy . } & 3 ; 3.4 & \text { Adam 26 } \\ \text { I want Paul to drink. } & 3 ; 3.18 & \text { Adam 27 }\end{array}$

The consistency of Adam's usage here clearly suggests that he is relying on complex, pre-compiled formulae. He appears to have both a [(do) (you) want NP VP?] "suggestion" schema and a [I (don't) want NP VP] "request" schema. In fact, the prototypical form of these schemas is even more narrowly defined: for instance, 
168 of Adam's total 214 "suggestions" feature me as the direct object. Similarly, Adam's unadult-like omission of the complementizer to is disproportionately correlated with the "suggestion" schema, accounting for $194(95 \%)$ of the 205 such omissions with want $+\mathrm{NFCC}$; conversely, only $13(14 \%)$ of the 90 correct uses of $[$ want to $+\mathrm{NFCC}]$ occur in the "suggestion" schema.

The use of see tends to be more varied than that of want, though again there is a bias for uses with $1^{\text {st }}$ and $2^{\text {nd }}$ person subjects. The verb is often used to monitor and maintain joint attention between child and addressee, and most of the children use see regularly, if not exclusively, for this purpose. Sarah uses see+NFCC largely to focus attention on herself: 15 of her 24 see+NFCC utterances occur as part of a [wanna see me VP?] schema, as in (5).

$\begin{array}{lll}\text { want to see me roller+skate ? } & 4 ; 0.5 & \text { Sarah } 87 \\ \text { wan(t) }(\mathrm{t}) \text { a see me make an f@1 ? } & 4 ; 2.28 & \text { Sarah 98 } \\ \text { wan(t) }(\mathrm{t}) \text { a see me write \# make water ? } & 4 ; 2.28 & \text { Sarah 98 } \\ \text { you wan(t) }(\mathrm{t}) \text { a see me make a house ? } & 4 ; 3.19 & \text { Sarah 101 } \\ \text { you wan(t) (t)a see me make a \# straight line ? } & 4 ; 3.26 & \text { Sarah 102 } \\ \text { you wan(t) (t)a see me write Sarah? } & 4 ; 4.25 & \text { Sarah 106 }\end{array}$

Adam's use of want and Sarah's use of see are compelling examples of narrow scope formulae; however, it might be a mistake to assume that these formulae represent all the children know about the way these verbs work with NFCCs. Sarah's use of see + NFCC, for example, is not limited to one routine, and she does occasionally vary both the arguments and the form of the verb (e.g. see the birdie drinking 3;10; let me see you open it 4;1). And even when Adam's use of want + NFCC is completely rigid, it's not clear that he can't understand the verb in other uses as well. What is clear is that these sorts of precompiled formulae make it easier for children to compose increasingly complex utterances on line for an increasingly wide variety of situations.

In this light, children's formulaic language need not be merely a sign of grammatical naiveté (though it may be that as well)-it is also a basic tool for the development of more sophisticated grammatical abilities. Narrow scope formulae allow children to break into complex syntax without having to compose complex sentences from scratch. Once they master a fixed formula, they can gradually learn what sorts of substitutions it affords, what sorts of constituents it contains, and what sorts of grammatical relations hold between them. In this sense, rigid formulae provide the foundation on which abstract and flexible constructions are built.

This process is evident in the way particular predicates come to combine with increasingly complex constituents over the course of development. For example, the make+NFCC constructions from Nina in (6) and Adam in (7) reveal a clear progression from simple, linear slot-and-frame patterns to complex, hierarchically organized structures. Early uses, as in $(6 a, 7 a)$, have no inflection or expressed subject, and feature a stripped down complement with a pronoun and an intransitive 
verb. Examples like those in (6b, $7 \mathrm{~b}$ ) feature more complex constituents, with overt subjects and auxiliary constructions in the matrix clauses, and postverbal adjuncts and complements in the NFCC itself. The crowning achievements come in $(6 \mathrm{c}, 7 \mathrm{c})$, where the compound complements of the matrix verb make suggest some real understanding of the constituency of the NFCC as a whole, and of the NFCC as a constituent.
a. make her stand up .
(Nina) $\quad 2 ; 0.24$
make a sit down .
$2 ; 0.24$
b. let's make him fly on this house .
$2 ; 9.21$
did the band+aid make it feel better?
$2 ; 9.21$
you can't make \# make these wheels move .
$2 ; 9.21$
c. let's make them sit down and talk \# Mommy .
$2 ; 11.6$
let's make the little doggy stand up and the mother stand up . 3;0.3
a. make it walks . make him run
b. I gon make you drive on it .
dis sometimes \# makes me cry .
c. dat makes it stick out and stay up .

(Adam) $2 ; 11.28$

$3 ; 0.11$

By the time Nina and Adam can manipulate these complex constituents, they have had months of practice with simpler substitutions in the same structures.

All seven children use the verb help with an NFCC at least once, and all of them use it specifically to request (or demand) assistance. Abe is particularly prolific with this use: out of 149 utterances with the verb help, Abe produces 43 distinct tokens with an NFCC, and of these $31(72 \%)$ are (in)direct requests or imperatives, as in (8).

(8) Abe's [...(you)...help me VP] Construction

I can't find it, Dad, you help me find it, ok ?

help me take my sock off .

can you help me put it back in?

$3 ; 1.1$

will you help me find a hockey stick?

are you gonna help me put em back in ?

you need to help me put em up I'm gonna do just two of em . $3 ; 8.2$

how'd you like to help me do wings for that $[/]$ for that arrow ? $3 ; 9.12$

know what you could help me do?

This data clearly shows that Abe has learned to use a specific construction with the verb help for a specific type of speech act. There is little evidence here that Abe has an adult-like syntactic representation for these sentences, or even that he understands the basic pragmatic principles governing his "indirect" speech acts. Rather Abe has a pivot-like help me $X$ construction, which he productively 
combines with bare VP complements for particular pragmatic purposes. On the other hand, Abe's use of help+NFCC is not entirely rigid either: his earliest such utterance features a $1^{\text {st }}$ person subject - I help my mommy cooking $(2 ; 6.4)$ - and later uses even include inanimate $3^{\text {rd }}$ person subjects-the candy we took to the movie helps you grow, $(3 ; 8.17)$. Indeed, the significance of the narrow scope [help $m e X]$ formula is not so much that it reveals Abe's grammatical limitations, but rather that it provides a handy framework for further syntactic development. By relying on a well-entrenched, precompiled formula, Abe is able to experiment with a range of syntactically complex embedding constructions - can you $X$, will you $X$, are you gonna $X$, you need to $X$, how'd you like to $X$, etc.-all of which require a complement of the same syntactic type and all of which fulfill analogous pragmatic functions. In this sense, the very simplicity of Abe's formulaic usage actually lays the foundation for his mastery of more complex and abstract structures.

\section{Early Agrammaticality and Groping}

Children's earliest combinations are occasionally among their most creative, or at least their most anomalous. The examples in (9) illustrate some of the unusual liberties children take with basic word order in NFCC constructions.

$\begin{array}{lll}\text { I sock put on . } & 1 ; 7 & \text { Eve 4 } \\ \text { mine take out . } & 2 ; 3.18 & \text { Adam 2 } \\ \text { outside put book. } & 2 ; 4.3 & \text { Adam 3 } \\ \text { take it Nina away. } & 2 ; 0.10 & \text { Nina 5 } \\ \text { cheek put it on. } & 2 ; 3.28 & \text { Nina 19 } \\ \text { put in my hair my barrette } & 2 ; 2.14 & \text { Peter 9 } \\ \text { we put in the glasses in the milk } & 2 ; 8.23 & \text { Naomi 70 } \\ \text { it throw away? } & 3 ; 3.20 & \text { Sarah 054 }\end{array}$

Braine (1976) refers to such apparently free word orders as groping patterns. If grammar is learned from experience, this sort of freedom makes sense early in grammatical development. Early on, when children have only a small and heterogeneous set of concrete constructions at their disposal, they will lack reliable patterns on which to model new utterances. And although local consistency requires that children should conform to the usages they know, global consistency predicts that children's utterances may be less constrained when they know fewer usages. The smaller the repertoire of constructions, the harder it is to recognize general patterns uniting them, so when children do come up with novel combinations, they will be free to combine them in any way that suits their pragmatic purposes. In this sense, groping constructions are not really ungrammatical, but rather agrammatical.

Such uses need not be entirely random. In general, groping may occur whenever a child has not yet mastered the combinatorial niceties of a given construction. The examples in (10) reveal a pattern of innovations where children have begun to use 
verb+particle constructions, but have not yet learned that light, pronominal objects obligatorily precede the particle.

$\begin{array}{ll}3 ; 1.9 & \text { Adam 22 } \\ 2 ; 1.1 & \text { Naomi 44 } \\ 2 ; 2.6 & \text { Nina 13 } \\ 2 ; 3.28 & \text { Nina 19 } \\ 1 ; 11.7 & \text { Peter 04 }\end{array}$

Presumably, the various verb+particle combinations here have been learned as units to which the children simply add a pronominal object. It is worth noting that most of these children also used the [V NP Particle] order at the time of these utterances, though usually with different verbs and particles: what these children apparently lack is a general schema for postposed particles, and a general understanding of when this schema is obligatory.

\section{Interference and Mixed Constructions}

Global consistency predicts that linguistic representations should maximize similarities across linguistic units: whether such similarities reflect deep structural relations or fortuitous surface resemblances, both will be grist for the mill of schema abstraction. False analogies and overgeneralizations are thus to be expected. Interference effects arise as a child's linguistic repertoire expands and constructions with similar formal and semantic properties compete to license usage events. The basic principle seems to be that utterance types which share some features are likely to share more, and the clearest manifestations of this are mixed constructions-nonce uses combining properties of two or more distinct constructions. Typical examples involve a verb or other lexical head appearing in a semantic frame or grammatical structure associated with some closely related expression. Thus, in (11), Peter incorrectly uses a to-infinitive with make after correctly using it in a similar causative construction with get; in (12) he makes the opposite mistake, erroneously using the same bare stem infinitive with get that he correctly uses with make just moments later.

$$
\begin{array}{lll}
\text { made him stand up. } & 2 ; 8.14 & \text { Peter 17 } \\
\text { I'm gonna get the cow to drink some milk. } & 2 ; 8.14 & \text { Peter 17 } \\
\text { *make a boy to ride on here. } & 2 ; 8.14 & \text { Peter 17 } \\
& & \\
& 3 ; 1.21 & \text { Peter 20 } \\
\text { *let's just get it stand. } & 3 ; 1.21 & \text { Peter 20 } \\
\text { I can make it stand. } & &
\end{array}
$$

Similarly, Nina in (13) and Adam in (14) produce NFCCs with peculiar gerundive complements in contexts where the gerundive complement has been primed by other, well-formed NFCC constructions. 
I don't want the water falling .

$*<$ I want a $>[/ /]$ I want my doll's waking up . $2 ; 5.28 \quad$ Nina 31

I saw a duck swimming in (th)e water .

$3 ; 0.25 \quad$ Adam 21

*why you goin $(\mathrm{g})$ put truck parking?

These sorts of errors, though very common, are rarely very productive. But while they may reflect mere momentary confusions, they also clearly depend on some implicit recognition of the relations among NFCC constructions.

Interestingly, certain types of confusion are quite common across subjects. For instance, children regularly seem to overextend causative predicates in NFCC constructions. Thus in (15) make, which normally requires a verbal or stative complement, shows up with a locative complement. Similarly, in (16), children use put (='cause $\mathrm{X}$ to be located at $\mathrm{Y}$ ') with stative complements, and in (17) give $\left(={ }^{\text {ccause }} \mathrm{Y}\right.$ to have $\mathrm{X}$ ') with locatives.

(15)

I \# I make cream on dolly's hair. make the duck off.

(16) I'm gonna put my suitcase full of stuff . I tryin $(\mathrm{g})$ put the sink off .
2;3.28 Nina 19

$3 ; 5.20$ Sarah 63

3;3.28 Abe 089

3;7.23 Sarah 070

(17) I am I'm gonna give it up there at the ceiling, see?

I give milk in .

4;6.19 Abe 185

2;3.28 Nina 19

I \# feed xxx (s)paghetti \# on my leg .

2;10.2 Adam 15

Since many matrix predicates allow two or more different types of X-comp (e.g. get allows stative, locative and verbal X-comps) this would appear to be a wellmotivated type of overextension. Indeed, it is striking that most of the seven children come up with the same (or very similar) overextensions.

\section{Persistence and Constructional Blending}

While mixed constructions are fairly common, they also tend to be somewhat fleeting in their overall effect. Where a schema is supported by a relatively small number of instances, its potential to license new utterances will be relatively weak; but where schemas capture robust similarities across a large set of utterance types they should be productive and resilient. Consistency predicts that the productivity of any schema should be a function of its global motivation in a range of exemplars and its overall compatibility with local consistency.

It is interesting in this light to consider Sarah's (e)rase $X$ off and Nina's wear $X$ on constructions in (18-19), both of which are produced over a period of eight 
months or more, and both of which are motivated by a family of well-entrenched and closely related constructional routines.

(18) Sarah: (e)rase $X$ off: 7 tokens; 4;3 - 4;11

can you erase dis off?

$4 ; 3.13$ Sarah 100

$\& c$ \# can I (e)rase the red off?

$4 ; 3.13$ Sarah 100

(e)rase it off.

$4 ; 4.11$ Sarah 104

I got ta (e)rase some off.

$4 ; 4.25$ Sarah 106

for a minute \# to (e)rase that off.

$4 ; 7.0 \quad$ Sarah 116

$\mathrm{mmhm}$ \# I have to erase that off .

$4 ; 11.13$ Sarah 131

(19) Nina: wear $X$ on, 11 tokens; $2 ; 6-3 ; 3$

you wear gloves on in Mantha's house . $\quad 2 ; 5.26 \quad$ Nina 29

bears don't wear clothes on .

$2 ; 10.13$ Nina 36

you can wear this blanket on tonight . $\quad 2 ; 11.6 \quad$ Nina 39

no \# with my undershirt I wanna wear that on . 3;2.12 Nina 51

I want the kitties to wear clothes on . $\quad 3 ; 2.16 \quad$ Nina52

these kind of dresses that I'm wearing on . $\quad 3 ; 3.1 \quad$ Nina54

The examples in (20) show some precursors for Sarah's use of erase $X$ off. By the time Sarah starts using this construction at $4: 3.13$, she has (a) already used the verb erase correctly in simple transitives, (b) used the particle off with at least 10 other transitive predicates (among others, take, wipe, cut, get, pull, peel, pick), and (c) created at least three other novel $V X$ off combinations.

(20) a. just erase it.

$4 ; 3.7 \quad$ Sar 99

b. I take em off .

$3 ; 0.27 \quad$ Sar 42

wipe my boo+boo off.

$3 ; 1.3 \quad$ Sar 43

I wan(t) (t)a cut the corners off . $\quad 4 ; 1.28 \quad$ Sar 93

how do you get the head off? $\quad 3 ; 10.30 \quad$ Sar 83

I tryin $(\mathrm{g})$ pick it off .

$3 ; 7.16 \quad$ Sar 69

c. you can work this off huh \# Mommy ? $\quad 4 ; 0.14 \quad$ Sar 88

I got ta write some off.

$4 ; 2.28 \quad$ Sar 98

Similarly, by the age of $2 ; 6$, when Nina begins her wear $X$ on usage, she has been using wear in simple transitives for at least six months (21a), and has used the particle on with at least 6 distinct transitive verbs: 9 times with have (21b), 81 times with put (2lc), and once each with leave, need, make and keep (21d). And in most of these uses, on has the same idiomatic semantics it takes with wear, specifically denoting a state of being dressed.

(21) a. I want \# I want to wear it .

$2 ; 3.18 \quad$ Nina 18

what's he wearing?

$2 ; 3.28 \quad$ Nina 19

b. she have jamas@f fon.

$2 ; 2.6 \quad$ Nina 13

you have a blanket on and we go in a carriage . 2;2.28 Nina 15 

c. put dress on .
$2 ; 1.6 \quad$ Nina 09
let me have \# my put my pants on .
$2 ; 1.29 \quad$ Nina 12
d. leave it on ::
2;1.22 Nina 11
I made a basket on .
$2 ; 2.6 \quad$ Nina 13
her need this seat on \# ok ?
2;3.14 Nina 17
no \# I keep it on .
$2 ; 4.26 \quad$ Nina 23

Sarah and Nina's innovations here are, in fact, so well-motivated that it is hard to see why they are not part of the adult language, and it is easy to see why the girls might be reluctant to give up such seemingly natural usages.

\section{Conclusions}

I take my observations here to support three basic conclusions. First, early child grammar involves both rote-learning and complex creativity, and these are complementary rather than antithetical processes. Second, children need not depend on a conservative learning strategy: they will over-extend their grammars where the principles of consistency give them good reason to do so, and recovery from such overextensions may take a very long time. Finally, there is more to creativity than first meets the eye. In this paper I have identified four distinct types of linguistic creativity, all more or less directly observable in children's spontaneous performance data. Further study is of course required. The important point is that one may learn a great deal about children's grammatical competence just from a careful analysis of the ways children really do say the darnedest things.

\section{Acknowledgments}

Much of the research for this paper was conducted during my time at the Max Planck Institute for Evolutionary Anthropology. Earlier versions were presented at the Amsterdam Center for Language and Communication (October 2000) and at the ICLC in Santa Barbara (July 2001). I am grateful to members of those audiences, to the audience at BLS, and to Kirsten Abbot-Smith, Heike Behrens, Nancy Chang, George Lakoff, Elena Lieven, and Michael Tomasello for their comments, as well as to Patricia Brooks and Tess Wood for comments on an earlier draft. What imperfections remain are entirely my own responsibility.

\section{References}

Barlow, Michael \& Suzanne Kemmer (eds.). 2000. Usage based models of language. Stanford: CSLI Publications.

Bowerman, Melissa. 1988. The 'no negative evidence' problem: Ho do children avoid constructing an overly general grammar? In J. A. Hawkins (ed.) Explaining Language Universals , 73-101. Oxford: Basil Blackwell. 
Bowerman, Melissa. 1996. Argument structure and learnability: Is a solution in sight? Proceedings of the Berkeley Linguistics Society 22: 454-468.

Braine, Martin. 1971. On two types of models of the internalization of grammars. In D. I. Slobin (ed.) The Ontogenesis of Grammar: A theoretical symposium, 153-86. New York: Academic Press.

Braine, Martin. 1976. Children's first word combinations. Monographs of the Society for Research in Child Development. Chicago: University of Chicago Press.

Braine, Martin \& Patricia Brooks. 1995. Verb argument structure and the problem of avoiding an overgeneral grammar. In M. Tomasello \& W. Merriman (eds.) Beyond names for things: Young children's acquisition of verbs, 353-376. Hillsdale, NJ: Lawrence Erlbaum Associates.

Bybee, Joan \& Paul Hopper (eds.). 2001. Frequency and the emergence of linguistic structure. Amsterdam/Philadelphia: John Benjamins.

Fisher, Cynthia. 2002. The role of abstract syntactic knowledge in language acquisition: A reply to Tomasello (2000). Cognition 82: 259-78.

Israel, Michael, Patricia Brooks, \& Michael Tomasello. In progress. The ReVerb code book. Leipzig, Germany: Max Planck Institute for Evolutionary Anthropology.

Johnson, Christopher. 1999. Constructional grounding: The role of interpretational overlap in lexical and constructional acquisition. $\mathrm{PhD}$ dissertation, UC Berkeley.

Langacker, Ronald W. 1987, 1991. Foundations of cognitive grammar, vols. 1 and 2. Stanford, California: Stanford University Press.

Langacker, Ronald W. 1999. Grammar and conceptualization. Cognitive Linguistics Research 14. Berlin \& New York: Mouton.

MacWhinney, Brian. 1995. The CHILDES Project: Tools for analyzing talk. Hillsdale, NJ: Erlbaum.

Pine, Julian, Elena Lieven, \& Caroline Rowland. 1998. Comparing different models of the development of the English verb category. Linguistics 36: 807-30.

Pinker, Stephen. 1989. Learnability and cognition: The acquisition of argument structure. Cambridge, Massachusetts: MIT Press/Bradford Books.

Tomasello, Michael. 2000a. Do young children have adult syntactic competence? Cognition 74: 209-253.

Tomasello, Michael. 2000b. The item-based nature of children's early syntactic development. Trends in Cognitive Science 4.

3101 Susquehanna Hall

University of Maryland

College Park, MD 20742

israel@wam.umd.edu 